\title{
Painless swelling of proximal interphalangeal joints in an adolescent child with preserved function and normal acute phase reactants
}

\author{
Georges El Hasbani1 ${ }^{1}$, Ali Jawad ${ }^{2} \mathbb{D}$, Imad Uthman ${ }^{1}(\mathbb{D}$ \\ ${ }^{1}$ Department of Internal Medicine, American University of Beirut Medical Center, Beirut, Lebanon \\ ${ }^{2}$ Department of Rheumatology, The Royal London Hospital, London, United Kingdom
}

A previously healthy 12 -year-old male patient presented with one-year history of bilateral (left more than right) swelling of the proximal interphalangeal (PIP) joints (Figure 1). The patient denied any tenderness with movement, nocturnal pain, or morning stiffness. The only findings on physical examination were swelling of the PIPs of the fingers. Laboratory investigations including complete blood count with differentials, erythrocyte sedimentation rate, rheumatoid factor, and antinuclear antibodies were normal. Hand radiographs revealed nonspecific swelling of the volar soft

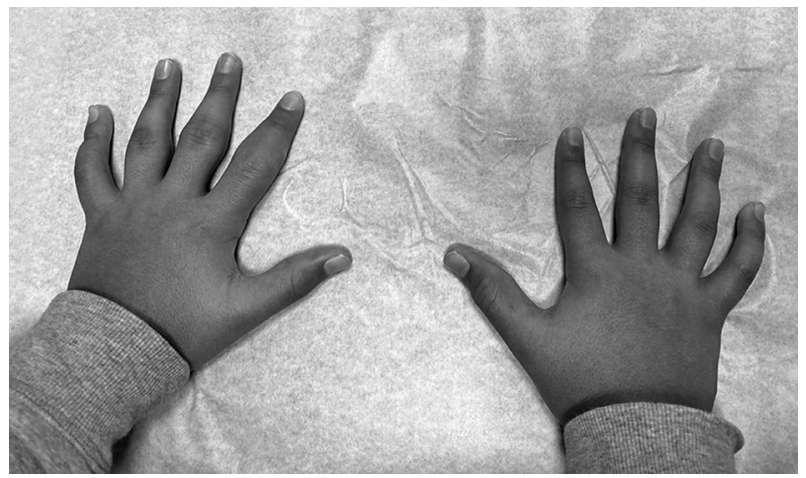

Figure 1. Swelling of patient's digits. tissues abutting the distal metaphysis of the proximal phalanges of the second to fifth fingers (Figure 2). The patient was diagnosed with Thiemann's disease (Online Mendelian Inheritance in Man: 165700).

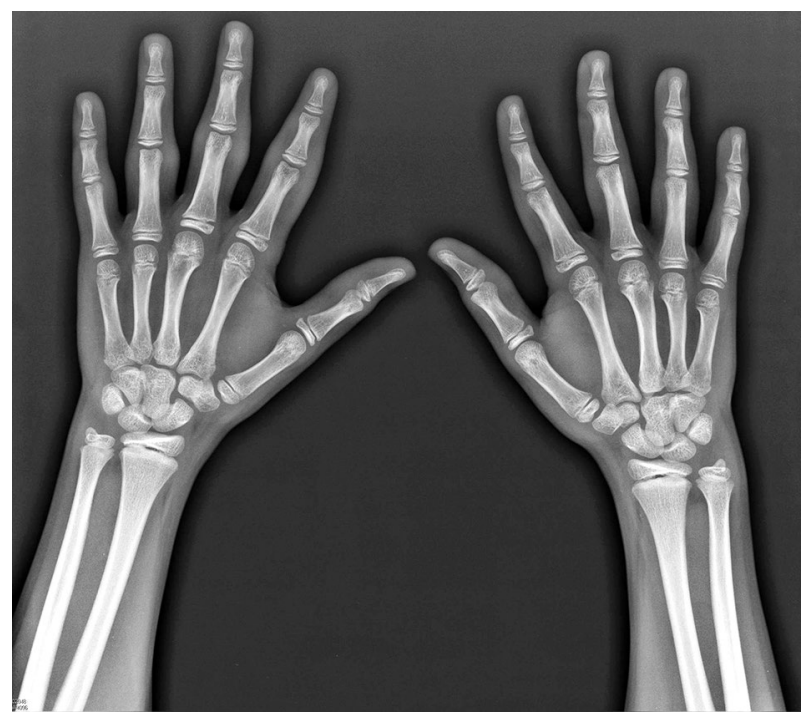

Figure 2. Hand X-ray showing nonspecific edema in volar soft tissues of proximal phalanges of second to fifth fingers.

Received: March 09, 2020 Accepted: April 30, 2020 Published online: September 04, 2020

Correspondence: Imad Uthman, MD. Department of Internal Medicine, American University of Beirut Medical Center, 11072020 Beirut, Lebanon. Tel: 96170604591 e-mail: iuthman@aub.edu.lb reactants. Arch Rheumatol 2021;36(1):144-145.

This is an open access article under the terms of the Creative Commons Attribution-NonCommercial License. which permits use. distribution and reproduction in any medium. provided the original work is properly cited and is not used for commercial purposes (http://creativecommons.org/licenses/by-nc/4.0/). 
First described in 1909, there has been 32 cases of Thiemann's disease reported in the literature characterized by clinical and radiological hand and foot epiphyseal abnormalities. ${ }^{1}$ Handa et al. ${ }^{2}$ proposed that Thiemann's disease appears before the age of 25 with PIP joint swelling and absence of elevated acute phase reactants. Radiologically, Thiemann's disease is characterized by fragmentation and broadening of the basal phalangeal epiphyses, which can be followed by joint space narrowing, premature physeal fusion, and phalangeal shortening. ${ }^{3}$ Clinicians should be aware of Thiemann's disease whenever an adolescent presents with painless swelling of the digits. An investigation involving radiograph and laboratory tests is crucial to eliminate possible differentials.

This manuscript has the ethical approval by the ethical review board of our institution.

\section{Declaration of conflicting interests}

The authors declared no conflicts of interest with respect to the authorship and/or publication of this article.

\section{Funding}

The authors received no financial support for the research and/or authorship of this article.

\section{REFERENCES}

1. Damseh N, Stimec J, O'Brien A, Marshall C, Savarirayan R, Jawad A, et al. Thiemann disease and familial digital arthropathy - brachydactyly: two sides of the same coin? Orphanet J Rare Dis 2019;14:156.

2. Handa R, Aggarwal P, Wali JP. A young boy with deforming arthropathy. Ann Rheum Dis 1998;57:79-80.

3. Melo-Gomes JA, Melo-Gomes E, Viana-Queiros M. Thiemann's disease. J Rheumatol 1981;8:462-7. 